Research Article

\title{
Investigation of Moisture Sensitivity and Conductivity Properties of Inductive Asphalt Mixtures Containing Steel Wool Fiber
}

\author{
Seyed Mohsen Hosseinian (D), ${ }^{1}$ Vahid Najafi Moghaddam Gilani $\left(\mathbb{D},{ }^{1}\right.$ \\ Peyman Mehraban Joobani $\mathbb{D}^{2}{ }^{2}$ and Mahyar Arabani ${ }^{2}$ \\ ${ }^{1}$ Highway and Transportation Engineering, Department of Civil Engineering, Iran University of Science and Technology, \\ Tehran, Iran \\ ${ }^{2}$ Highway and Transportation Engineering, Department of Civil Engineering, University of Guilan, Rasht, Iran
}

Correspondence should be addressed to Vahid Najafi Moghaddam Gilani; vahid.moghaddam90@gmail.com

Received 13 August 2020; Revised 27 September 2020; Accepted 19 October 2020; Published 31 October 2020

Academic Editor: Timothy O. Olawumi

Copyright (C) 2020 Seyed Mohsen Hosseinian et al. This is an open access article distributed under the Creative Commons Attribution License, which permits unrestricted use, distribution, and reproduction in any medium, provided the original work is properly cited.

\begin{abstract}
The construction of suitable roads in rainy areas has created problems in the construction process due to the low resistance of asphalt to moisture. To solve this problem, materials are commonly used that make mixtures resistant to moisture; however, these materials may reduce the dynamic resistance of asphalt. Therefore, materials should be used that, in addition to increasing the dynamic resistance, also increase the moisture resistance of asphalt mixtures. One of these materials used in this research is steel wool fiber (SWF), which in addition to creating conductive roads also could have a significant effect on moisture resistance. In this study, the impact of $2 \%, 4 \%, 6 \%, 8 \%$, and $10 \%$ SWF on the Marshall stability and moisture sensitivity of mixtures was investigated using the Marshall stability and indirect tensile strength (ITS) tests, respectively. Moreover, using SWF as a conductive fiber, the conductivity properties of asphalt mixtures were explored to find the optimal amount of electrical conductivity. The results of the Marshall stability test indicated that by increasing SWF contents, the stability of mixtures increased, compared with the base sample, and greater amounts of $6 \%$ SWF resulted in the reduction of the Marshall stability. The results of ITS showed that modification of bitumen by SWF increased ITS and tensile strength ratio (TSR) amounts of mixtures. 6\% SWF was the optimal amount for enhancing the resistance of asphalt mixtures to moisture sensitivity. The results of the electrical resistivity test showed that the resistivity had three phases: high resistivity, transit, and low resistivity. Mixtures containing less than $4 \%$ SWF illustrated an insulating behavior, with electrical resistivity greater than $7.62 \times 10^{8} \Omega \mathrm{m}$. At the transit phase, the resistivity of mixtures had a sharp reduction from $7.62 \times 10^{8} \Omega$.m to $6.17 \times 10^{4} \Omega$.m. Finally, $8 \%$ SWF was known as the optimal content for the electrical conductivity of mixtures.
\end{abstract}

\section{Introduction}

Damage caused by moisture is one of the prevalent failures in asphalt pavements. Moisture may weaken adhesion between aggregates and bitumen and separate them from each other. This damage is commonly known as stripping that may cause holes on the road surface and can lead to traffic accidents [1]. The durability of asphalt pavements is affected by these damages because bitumen tends to be stripped from the surface of aggregates and causes aggregates to become bitumen-free. The presence of water in asphalt pavements disrupts the bonding and results in increased moisture sensitivity $[2,3]$. The modification of bitumen helps to improve the behavior of asphalt mixtures [4-6]. Creating small cracks in asphalt pavements causes bigger damages. So, it is possible theoretically to repair cracks in the pavement by adding conductive fibers, enhancing its conductivity in order to enhance its self-healing degree [7]. Therefore, this study aims to indicate how the asphalt mixture conductivity and 
moisture resistance change by adding various amounts of conductive material.

Some asphalt pavements have self-healing properties. The healing phenomenon happens when stress or strain produced is large enough to cause damage. As soon as the loading caused failure is eliminated and the two crack faces are placed in contact, the release of the molecules starts from one side to the other side. The self-healing process continues until the microcracks are completely removed, and the healed materials have a resistance level of the raw material $[8,9]$.

Inductive asphalts (IAs) comprising steel wool fiber (SWF), as a new pavement substance, have some advantages in various areas, including maintenance [10-12], functional/ durability characteristics $[13,14]$, and service life $[15,16]$. The convenience of maintenance and efficiency is the significant advantage of IAs compared with common asphalts. SWFs are added to asphalt mixtures during the first manufacturing phase. Nevertheless, when microcracks are generated or these substances are not added at the manufacturing phase, some additional substances such as healing agents are required to seal and fill cracks in order to enhance healing $[17,18]$. Bitumen healing is reported greatly sensitive to moisture conditioning [19]. Some studies also indicated that the conductivity of asphalt mixtures depends on the amount of conductive fibers used and an excessive amount of conductive materials can result in the degeneration of the asphalt mixture characteristics [20]. Therefore, it is important to study the effect of conductive fibers on the simultaneous improvement of asphalt behaviors such as moisture performance and conductivity properties.

The healing mechanism of a crack includes an instant increase in loading transferability because of cohesion and adhesion, as well as following long-time healing because of molecular distribution through the interfaces [21]. One of the exterior factors that influence the healing mechanism is the presence of water absorbed on the faces of cracks. The water infiltration may result in cohesion and adhesion loss and therefore decrease the healing capacity. Moreover, the healing process may be decreased by interruptions of water in the dipole balance of asphalt mixtures by creating a bond with the greatly polar groups of the asphalt molecules or salts and ions which are water soluble and connected to the polar sections of asphalt mixtures [22].

Some studies have investigated the impact of moisture penetration into asphalt mixtures by the use of both computational and experimental approaches [23-27]. It was reported that the presence of moisture could result in damages in asphalt mixtures by displacement, detachment, $\mathrm{PH}$ instability, pore pressure, and hydraulic scour [28]. Some studies have tried to recover the moisture characteristics in asphalt mixtures damaged along with the investigation of the healing process $[16,19,29]$. The presence of moisture was stated harmful for microwave healing and induction of reinforced mixtures by fibers, although it enhanced the heating rate of the mixtures [16]. Moreover, conditioning of mixtures by moisture was illustrated to have a negative effect on the self-healing of bitumens [19]. By contrast, saturated samples in moisture were observed to recover from damages caused fatigue in an allowed sufficient rest time [25, 29]. In another study, moisture penetration had a nominal influence on multiple fracture-rehealing behavior [18]. Therefore, it is necessary to adopt a solution to improve the moisture and self-healing behaviors of mixtures.

Some studies have been conducted to examine the behavior of IAs containing SWF/steel fiber [7, 10, 30-36]. However, few studies have been conducted to investigate the moisture behavior in these asphalts containing SWF. Liu et al. performed a study to explore the mechanical behavior of porous asphalt using indirect tensile strength (ITS) as well as the conductivity of mixtures by the use of SWF. They indicated that $10 \%$ SWF was the optimal amount to achieve a satisfying ITS as well as an optimum conductivity [37]. Sun et al. investigated the healing characteristics of asphalt mixtures due to moisture damages using steel fiber and illustrated that the heating speed of mixtures with induction heating was improved at the water presence. They also stated that it is better for the mixtures to be healed in dry conditions compared with the water presence [16]. Li et al. examined the moisture conditioning impact on the healing and mechanical characteristics of asphalt mixtures containing 6\% SWF and indicated that there was no corrosion of SWF in asphalt mixtures after the moisture-induced sensitivity test. Moreover, the fracture energy and tensile strength were reduced after the test [36]. The significant point of these research studies is the various size of steel fiber that they used and also another difference between these studies and the present study is in the properties of SWF (e.g., diameter and average length) and asphalt mixtures as well as the tests conducted in this paper (such as electrical resistivity and Marshall stability).

The principal goal of the present study was to examine the impact of SWF amounts on the Marshall stability and moisture sensitivity of hot mix asphalt (HMA) in order to determine the optimal amount of SWF. Also, by adding SWF as a conductive fiber, the conductivity properties of asphalt mixtures were investigated to find the optimal amount of electrical conductivity.

\section{Materials and Methods}

2.1. Aggregate. Limestone aggregate was used in this research, and the grading of the aggregate was according to the ASTM standard that the nominal and maximum size of the aggregate is $12.5 \mathrm{~mm}$ and $19 \mathrm{~mm}$, respectively. The grading of the aggregate is presented in Figure 1, and the physical features of the aggregate are indicated in Table 1.

2.2. Bitumen. In this research, bitumen with a penetration grade of 60-70 prepared from the Jey Oil Refinery was used as the base bitumen, and its features are indicated in Table 2.

2.3. Modification of Bitumen. Steel wool fiber (SWF) as an electrically conductive fiber with the weight percentages of $2 \%, 4 \%, 6 \%, 8 \%$, and $10 \%$ was used to modify the bitumen properties; that is, the density, equivalent diameter, average 


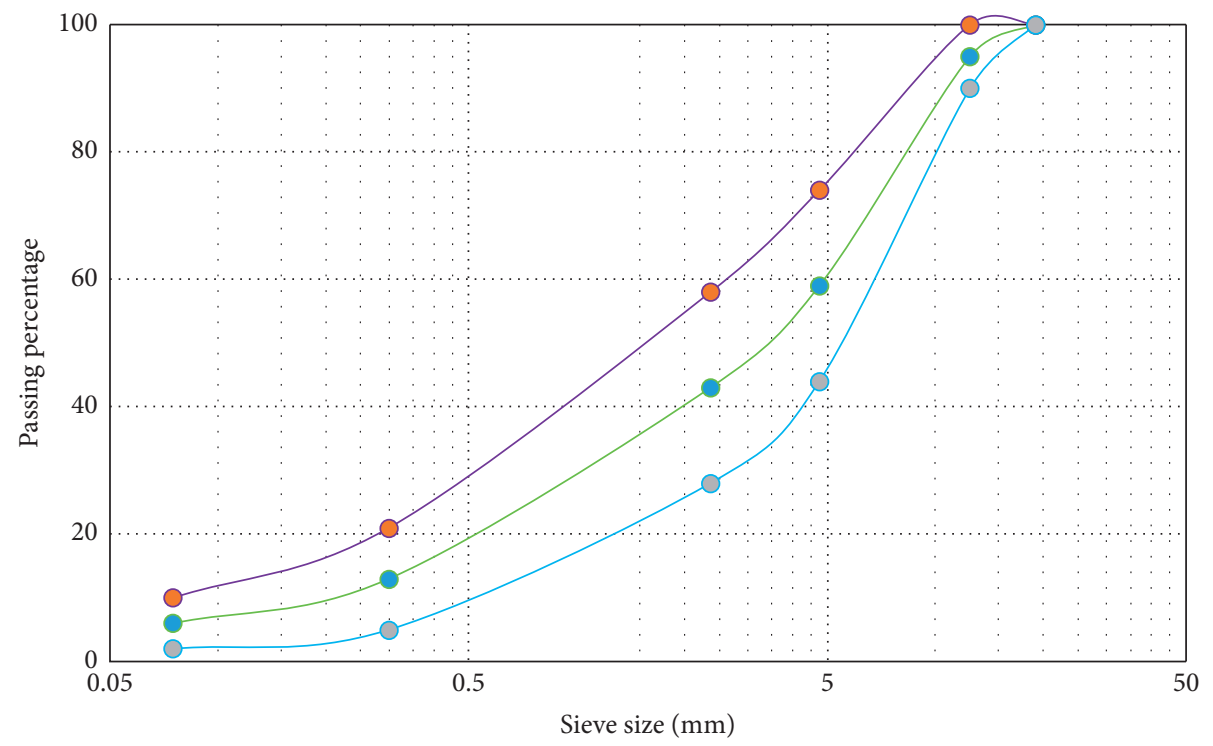

FIGURE 1: Applied grading of aggregate in the study.

TABLE 1: The physical features of the aggregate.

\begin{tabular}{lccc}
\hline Features & Standard & Limestone & Regulation limits \\
\hline Specific gravity (coarse aggregate) & & 2.60 \\
$\quad$ Effective & ASTM: C127 & 2.61 & - \\
Bulk & & 2.63 & - \\
$\quad$ Apparent & & 2.56 \\
Specific gravity (fine aggregate) & ASTM: C128 & 2.57 & - \\
$\quad$ Effective & & 2.60 & - \\
Bulk & ASTM: D854 & 2.56 & - \\
Apparent & ASTM: C131 & 28 & - \\
Specific gravity (filler) & ASTM: C127 & 0.8 & Maximum 30 \\
Maximum Los Angeles abrasion test & ASTM: D4791 & 3 & Maximum 2 \\
Maximum water absorption & ASTM: D5821 & 88 & Maximum 15 \\
Needle and flake particles & ASTM: C88 & 2 & Maximum 10 \\
Flat and elongated particles & & Maximum 15 \\
Sodium sulfate soundness & & & \\
\hline
\end{tabular}

TABLE 2: The features of the base bitumen.

\begin{tabular}{lcc}
\hline Properties & Standard & Base bitumen \\
\hline Penetration ratio & & 0.25 \\
Penetration $\left(100 \mathrm{~g}, 5\right.$ seconds, $\left.25^{\circ} \mathrm{C}\right), 0.1 \mathrm{~mm}$ & ASTM: D5 & 69 \\
Penetration $\left(200 \mathrm{~g}, 60\right.$ seconds, $\left.44^{\circ} \mathrm{C}\right), 0.1 \mathrm{~mm}$ & ASTM: D36 & 31 \\
Softening point $\left({ }^{\circ} \mathrm{C}\right)$ & ASTM: D1754 & 48 \\
Heat weight loss $(\%)$ & ASTM: D113 & 0.75 \\
Ductility $(\mathrm{cm})$ & ASTM: D92 & 114 \\
Flash point $\left({ }^{\circ} \mathrm{C}\right)$ & & 264 \\
\hline
\end{tabular}

length, and electrical resistivity of SWF were $7.8 \mathrm{~g} / \mathrm{cm}^{3}$, $70-130 \mu \mathrm{m}, 4.2 \mathrm{~mm}$, and $7 \times 10^{-7} \Omega . \mathrm{cm}$, respectively. First, the aggregate was heated for 24 hours at $150^{\circ}$ as well as bitumen and fibers were heated for 2 hours at $150^{\circ}$, and they were then mixed for 3.5 minutes at $150^{\circ}$ in the mixing bowl with $100 \mathrm{rpm}$ [38]. Figure 2 shows the SWF sample used in this research. Also, SWF used had the same approximate length, but the difference between the modified asphalt mixtures was in SWF weight percentages.

2.4. Asphalt Mix Design. The Marshall mix design method was used in this research to specify the optimal content of bitumen according to AASHTO T245 [39] and based on the 


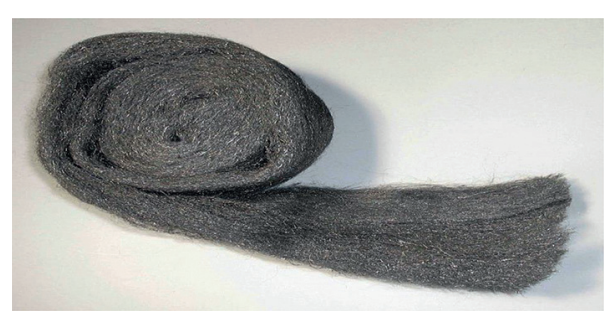

Figure 2: The SWF sample in this research.

average values of three different bitumens according to the highest Marshall strength, the highest specific gravity, and $4 \%$ air voids. The optimal bitumen percentage of samples was calculated according to Table 3 .

\section{Test Method}

In this research, the Marshall stability, moisture sensitivity, and electrical resistivity of asphalt mixtures modified by SWF with $2 \%, 4 \%, 6 \%, 8 \%$, and $10 \%$ weight percentages were investigated. First of all, the Marshall stability test was performed to determine the stability of the base and modified mixtures. In this test, each base or modified bitumen (with different percentages of $4.5 \%, 5 \%, 5.5 \%$, and $6 \%$ ) was modified by SWF with percentages of $0 \%, 2 \%, 4 \%$, $6 \%, 8 \%$, and $10 \%$, and 3 samples were constructed for each composition so that finally 72 samples were made for the Marshall stability test. After the Marshall stability test, 48 samples were made for the ITS test to evaluate the moisture sensitivity of mixtures. Also, 18 samples were constructed for determining the electrical conductivity of mixtures. The number of replicates of each test is presented in Table 4.

3.1. Marshall Stability Test. The Marshall stability test, according to ASTM D6927, was applied to examine the physical and mechanical characteristics of mixtures [40]. In the test, by immersing the mixtures in a $60^{\circ}$ water bath for $45 \mathrm{~min}$, the mixtures were prepared.

3.2. ITS Test. In this research, the ITS test was applied to examine the behavior of asphalt mixtures to damages caused by moisture based on AASHTO T283. For performing the test by the modified Lattmann, three mixtures were made in dry conditions and three in wet conditions (with distilled water). The saturated percentage of samples should be approximately $70 \%$ to $80 \%$. Loading was performed in this test at a $5.08 \mathrm{~cm}$ rate per minute until the specimens break. The loading amount was filed at the failure moment. By the use of equation (1), the ITS value of the specimens was obtained [6]:

$$
\text { ITS }=\frac{2 P}{t \pi d},
$$

where $P$ is the maximum load at the moment of failure $(\mathrm{kN})$, $d$ represents the mixture diameter $(\mathrm{m})$, and $t$ presents the mixture thickness (m). The moisture sensitivity of the samples with the average ITS ratio of the wet to dry specimens was obtained from the following equation [41]:

$$
\mathrm{TSR}=\frac{\text { ITS }_{\text {wet }}}{\mathrm{ITS}_{\text {dry }}} \times 100,
$$

where ITS $_{\text {wet }}$ presents the average ITS value in the wet sample $(\mathrm{kPa})$ and ITS $_{\text {dry }}$ represents the average ITS value in the dry sample $(\mathrm{kPa})$.

3.3. Electrical Resistivity Test. The measurements of electrical resistivity were performed at $21^{\circ}$ (room temperature). The mixtures were subjected for 8 hours at $40^{\circ}$ to eliminate moisture and preclude SWFs from corrosion on the surface of mixtures. A digital multimeter and a resistance tester were utilized for measuring the resistance lower and higher $36 \times 10^{6} \Omega$, respectively. Two electrodes made with a rectangular copper plate at the size of $100 \times 160 \mathrm{~mm}$ were in conjunction with wires and connected with the resistance tester in order to test resistance. These two were put at both ends of the mixture for measuring the electrical resistance. The end effects were regarded as insignificant, and the electric field was supposed to be fixed. From the second Ohm's law, the electrical resistivity was achieved, according to the following equation [42]:

$$
\rho=\frac{S R}{L}
$$

in which $L$ presents the internal electrode distance (m), $\rho$ represents the electrical resistance $(\Omega . \mathrm{m}), R$ presents the calculated resistance $(\Omega)$, and $S$ illustrates the electrode conductive area $\left(\mathrm{m}^{2}\right)$.

\section{Results and Discussion}

4.1. Marshall Stability. The results of the application of the Marshall stability of mixtures containing SWF are illustrated in Figure 3. As is clear, by increasing SWF contents, results demonstrated that the Marshall stability enhanced up to $14.12 \mathrm{KN}$ that is the maximum amount for samples containing 6\% SWF. An increase in SWF content resulted in the reduction of stability of mixtures under compressive stresses, which could be related to the increment in bitumen viscosity in the presence of SWF. As is clear from Figure 3, the viscosity of bitumen had a straight relationship with SWF up to $6 \%$. More than this content, the modulus of asphalt mixtures was increased and it caused to strengthen, but by increasing SWF amounts to $8 \%$ or $10 \%$, the viscosity 
TABLE 3: The optimal bitumen percentage of samples.

\begin{tabular}{lccccc}
\hline $\begin{array}{l}\text { SWF } \\
\text { contents }\end{array}$ & $\begin{array}{c}\text { Marshall maximum } \\
\text { strength }\end{array}$ & $\begin{array}{c}\text { Bitumen percentage corresponding to } \\
\text { Maximum specific gravity of the } \\
\text { mixture }\end{array}$ & $\begin{array}{c}\text { 4\% air } \\
\text { voids }\end{array}$ & $\begin{array}{c}\text { Voids filled with asphalt } \\
\text { (VFA) }\end{array}$ & $\begin{array}{c}\text { Optimal bitumen } \\
\text { percentage }\end{array}$ \\
\hline 0 & 5.2 & 5.1 & 4.5 & 4.8 & 4.9 \\
2 & 5.1 & 5.0 & 4.5 & 5.0 & 4.9 \\
4 & 5.1 & 5.0 & 4.5 & 5.0 & 4.9 \\
6 & 5.2 & 5.1 & 4.6 & 4.7 & 4.9 \\
8 & 5.2 & 5.2 & 4.7 & 4.9 & 5.0 \\
10 & 5.2 & 5.2 & 4.7 & 4.9 & 5.0 \\
\hline
\end{tabular}

TABLE 4: Types and replicate numbers of the tests used in this research.

\begin{tabular}{lccc}
\hline Test & \multicolumn{1}{c}{ Purpose of test } & Number of replicates & Number of samples \\
\hline Marshall stability & Determination of asphalt mixture stability & 3 & 72 \\
Indirect tensile strength & Determination of moisture sensitivity & 4 & 48 \\
Electrical resistivity & Determination of electrical conductivity & 3 & 18 \\
\hline
\end{tabular}

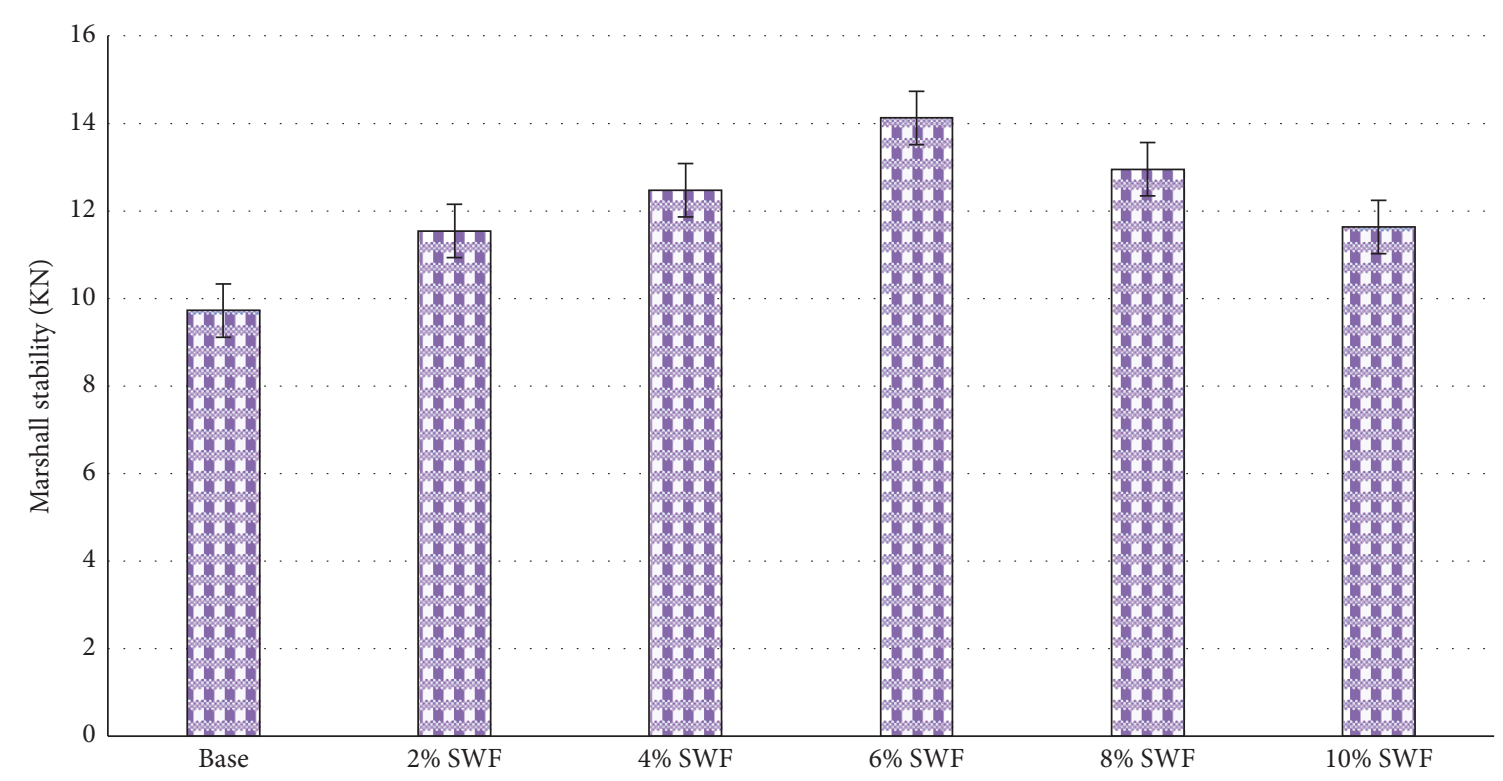

Figure 3: The Marshall stability results of unmodified and modified asphalt mixtures.

of bitumen was declined and the asphalt mixtures tended to fail and fracture.

4.2. ITS. The results corresponding to the ITS values of the samples under the wet and dry conditions are illustrated in Figure 4. As can be seen, with the cohesion loss of the asphalt mixtures due to the exposure of the samples to moisture, the ITS amounts of the samples in wet conditions were reduced compared with those of samples in dry conditions. On the other, the ITS amounts in both wet and dry conditions were increased by modifying the properties of bitumen with SWF so that by adding SWF, the cohesion and adhesion of mixtures were increased and caused it to obtain a higher moisture resistance over the unmodified mixtures. The ITS value of the mixtures modified with $2 \%, 4 \%, 6 \%, 8 \%$, and $10 \%$ SWF was increased by $4.49 \%, 9.51 \%, 15.13 \%, 10.46 \%$, and $6.14 \%$ in dry conditions and $14.15 \%, 31.27 \%, 47.98 \%$, $33.29 \%$, and $19.27 \%$ in wet conditions, respectively, compared with the base sample, and the highest increase in the ITS value was visible in the modified samples with $6 \%$ SWF. The results showed that the addition of SWF more than $6 \%$ reduced the amount of ITS in dry and wet conditions because adding excessive SWF contents decrease the bitumen film thickness as well as air voids of asphalt samples, resulting in an unappropriated adhesion in the asphalt system [37].

Figure 5 illustrates the TSR amounts of the samples under the dry and wet conditions. These values indicate the importance of the presence of SWF and its effect on moisture 


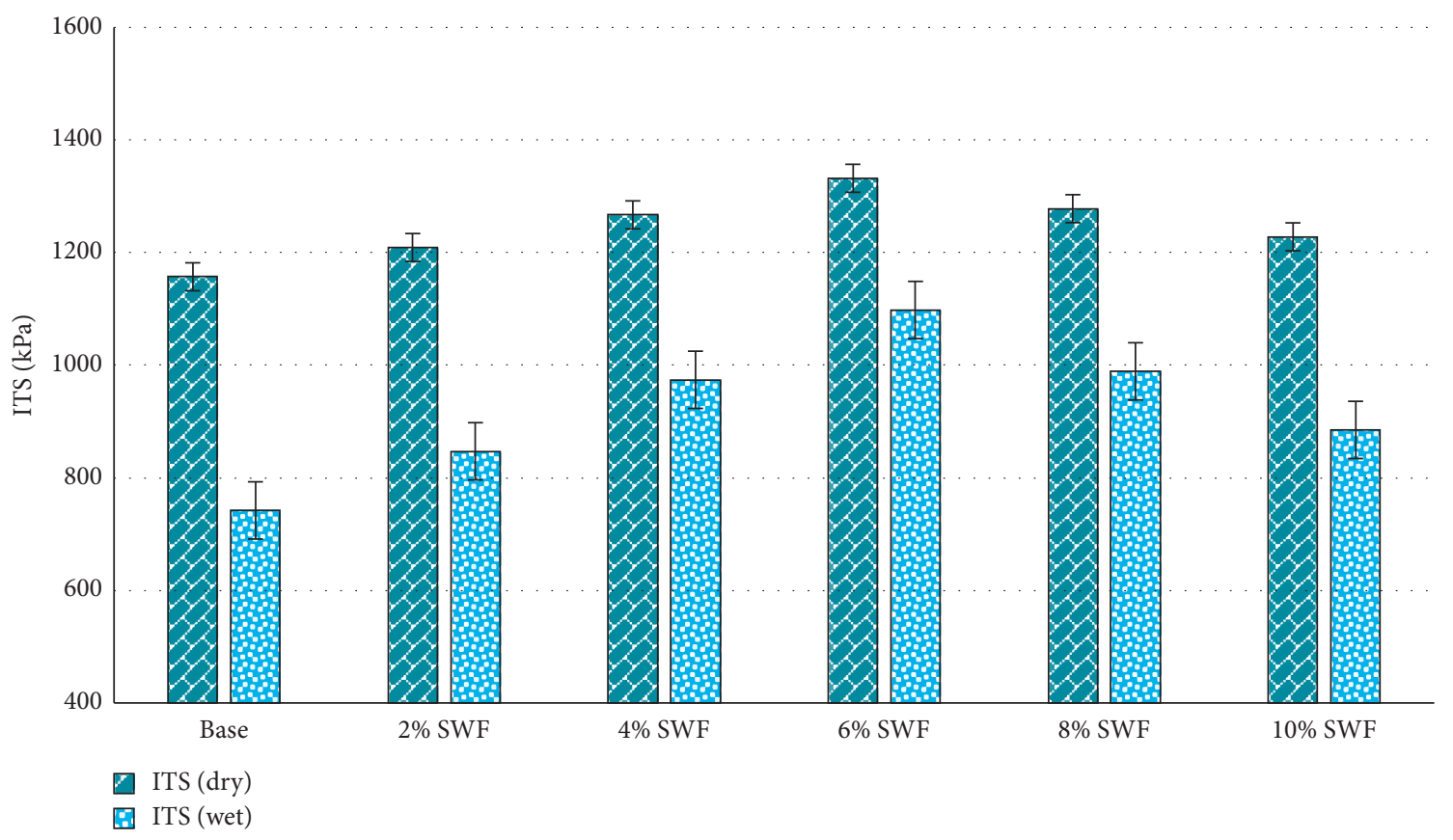

FIGURE 4: The ITS test results in the dry and wet conditions.

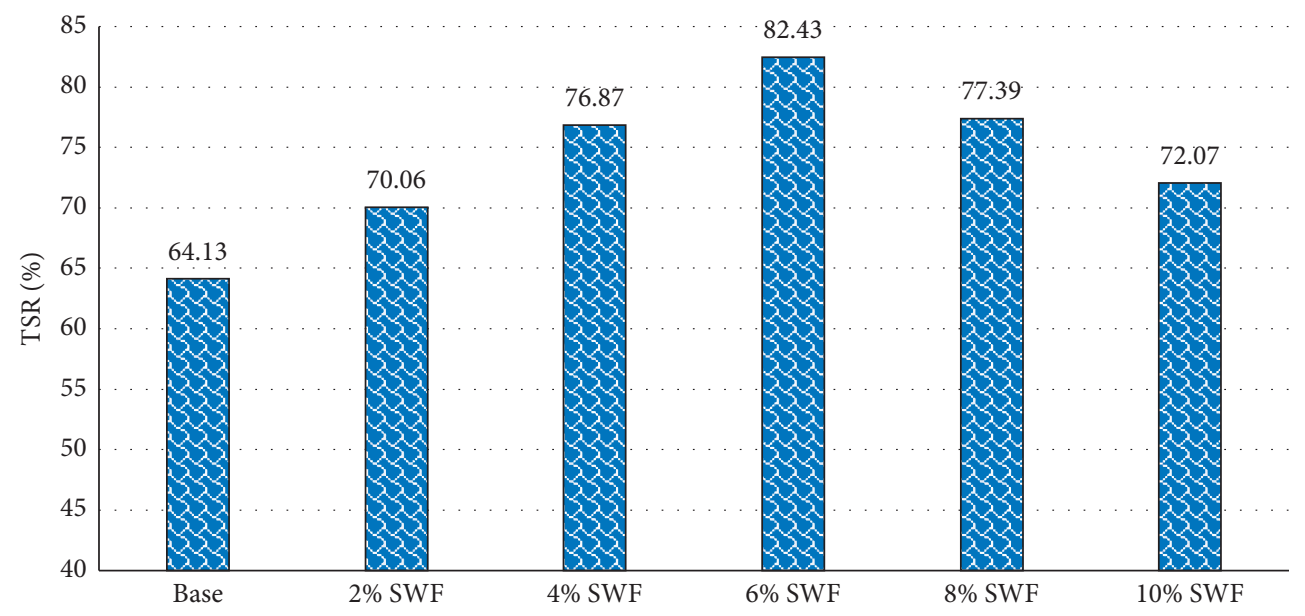

FIGURE 5: The TSR results of unmodified and modified asphalt mixtures.

sensitivity. As is clear, the TSR amounts of the modified samples with $2 \%, 4 \%, 6 \%, 8 \%$, and $10 \%$ SWF compared with the base sample increased by $9.24 \%, 19.87 \%, 28.54 \%$, $20.67 \%$, and $12.38 \%$, respectively. The application of $6 \%$ SWF indicated the best impact on enhancing the resistance of asphalt mixtures to moisture sensitivity.

Based on the values obtained from Figure 5, it can be concluded that the TSR values have increased significantly, which may be due to the fact that SWFs with their small diameter have filled some of the pores of asphalt samples and prevented water penetration into them. On the other hand, an enhancement in the TSR may be due to the fact that steel fibers are hydrophobic and do not absorb any water. It should also be noted that the amount of $6 \%$ additive was provided as the optimal amount to increase the moisture resistance of asphalt mixtures.

4.3. Electrical Resistivity. The impact of SWF contents on the electrical resistivity of mixtures is presented in Figure 6. The resistivity of mixtures showed three phases. The first phase illustrated a high resistivity of mixtures with SWF contents less than $4 \%$, followed by the transit phase with $4-8 \%$ SWF contents and the low resistivity phase with SWF contents more than $8 \%$. Mixtures containing less than $4 \%$ SWF illustrated an insulating behavior, with electrical resistivity greater than $7.62 \times 10^{8} \Omega$.m. At the transit phase, the resistivity of mixtures had a sharp reduction from $7.62 \times 10^{8} \Omega$.m to $6.17 \times 10^{4} \Omega$.m. Based on the results in Figure 6, the mixture 


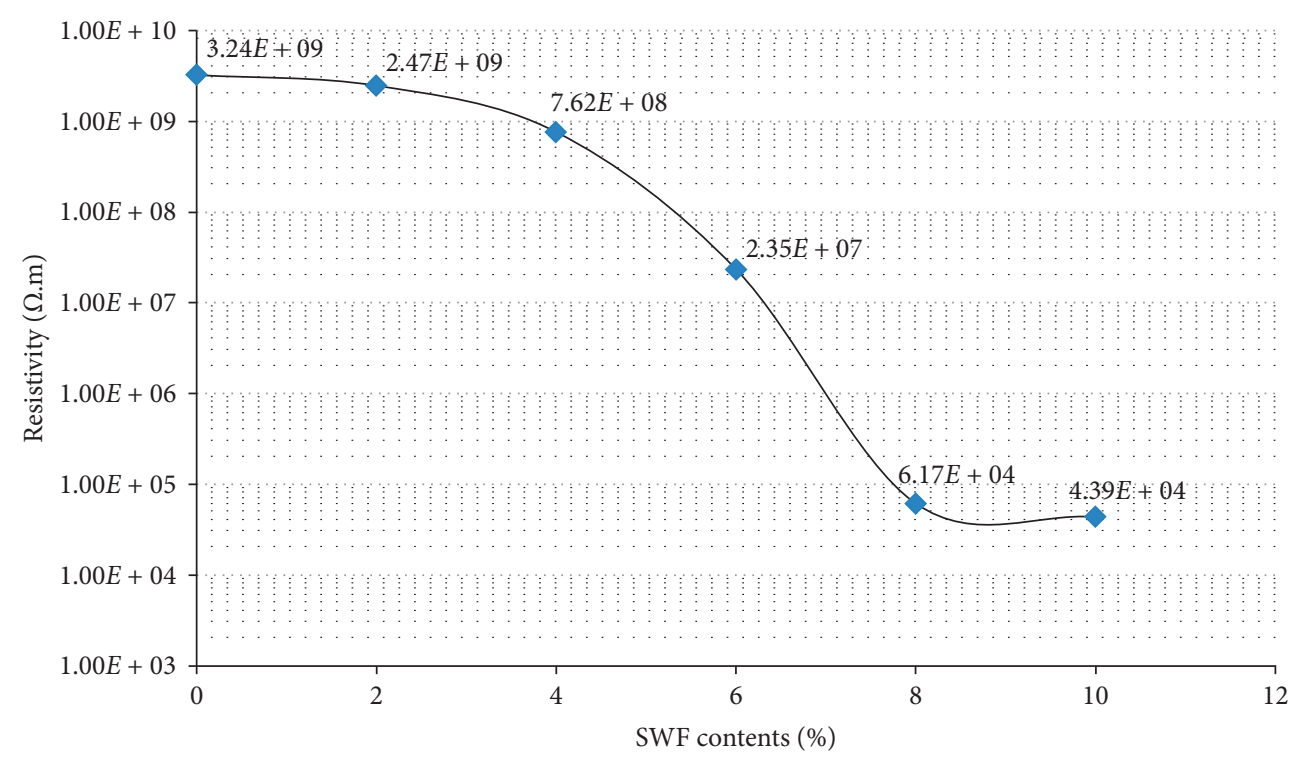

FIGURE 6: Changes in electrical resistance of SWF modified mixtures relative to SWF contents.

containing more than $8 \%$ SWF did not have much effect on reducing the electrical resistance and as can be seen, the electrical resistivity of the mixture containing $10 \%$ SWF was slightly less than the mixture with $8 \%$ SWF. Due to the deterioration of the dynamic properties of asphalt mixtures with excessive increase in SWF, 8\% SWF was known as the optimal content for the electrical conductivity of mixtures. In fact, the optimal amount of electrical conductivity is the maximum amount that does not show a significant change in the electrical resistance of the mixtures by increasing SWF. Also, in this amount, the asphalt mixture is in its best selfhealing state in case of heating induction. The significant point is that the optimum amount of SWF for modifying the moisture and electrical resistivity of hot mix asphalt mixtures is less than amounts that modified porous asphalt mixtures in the study of Liu et al. [37].

\section{Conclusion}

In this research, the performance of moisture and electrical resistivity of asphalt mixtures was investigated under the influence of SWF additive. The significant findings of the research are as follows:

(i) The results of the Marshall stability test indicated that by increasing SWF contents, the stability of mixtures increased, compared with the base sample. However, this increment was obvious up to $6 \%$ SWF and greater amounts resulted in the reduction of the Marshall stability.

(ii) The results of the ITS test showed that modification of bitumen with SWF increased the ITS and TSR amounts of the mixtures.

(iii) The ITS value of the mixtures modified with $2 \%, 4 \%$, $6 \%, 8 \%$, and $10 \%$ SWF was increased by $4.49 \%$, $9.51 \%, 15.13 \%, 10.46 \%$, and $6.14 \%$ in dry conditions and $14.15 \%, 31.27 \%, 47.98 \%, 33.29 \%$, and $19.27 \%$ in wet conditions, respectively, compared with the base sample.

(iv) 6\% SWF indicated an optimal amount for enhancing the resistance of asphalt mixtures to moisture sensitivity.

(v) The results of electrical resistivity of mixtures showed that the resistivity had three phases: high resistivity, transit, and low resistivity phases, which were related to SWF contents less than $4 \%, 4-8 \%$, and more than $8 \%$, respectively.

(vi) Mixtures in the first phase demonstrated an insulating behavior, with electrical resistivity greater than $7.62 \times 10^{8} \Omega$.m, and at the transit phase, the resistivity had a sharp reduction. Finally, $8 \%$ SWF was known as the optimal content for the electrical conductivity of mixtures.

\section{Data Availability}

The data used to support the findings of this study are currently under embargo while the research findings are commercialized. Requests for data, 3 months after publication of this article, will be considered by the corresponding author.

\section{Conflicts of Interest}

The authors declare that they have no conflicts of interest.

\section{Acknowledgments}

The authors thank the JEY Oil Refining Company for their generous help during this study.

\section{References}

[1] H. Taherkhani and M. Tajdini, "Comparing the effects of nano-silica and hydrated lime on the properties of asphalt 
concrete," Construction and Building Materials, vol. 218, pp. 308-315, 2019.

[2] A. Diab, Z. You, Z. Hossain, and M. Zaman, "Moisture susceptibility evaluation of nanosize hydrated lime-modified asphalt-aggregate systems based on surface free energy concept," Transportation Research Record: Journal of the Transportation Research Board, vol. 2446, no. 1, pp. 52-59, 2014.

[3] D. Cheng, Surface Free Energy of Asphalt-Aggregate System and Performance Analysis of Asphalt Concrete Based on Surface Free Energy, Texas A\&M University, College Station, TX, USA, 2003.

[4] H. Behbahani, V. N. M. Gilani, R. Salehfard, and D. Safari, "Evaluation of fatigue and rutting behaviour of hot mix asphalt containing rock wool," International Journal of Civil Engineering, vol. 18, no. 11, pp. 1293-1300, 2020.

[5] H. Behbahani, G. H. Hamedi, and V. N. Moghaddam Gilani, "Evaluating the surface free energy and moisture susceptibility of modified asphalt mixtures with nano hydrated lime under saturated conditions with deicer materials and distilled water," Journal of the Indian Chemical Society, vol. 97, pp. 791-798, 2020, In press.

[6] H. Behbahani, G. H. Hamedi, and V. Najafi Moghaddam Gilani, "Predictive model of modified asphalt mixtures with nano hydrated lime to increase resistance to moisture and fatigue damages by the use of deicing agents," Construction and Building Materials, vol. 265, Article ID 120353, 2020.

[7] Áa García, E. Schlangen, M. van de Ven, and Q. Liu, "Electrical conductivity of asphalt mortar containing conductive fibers and fillers," Construction and Building Materials, vol. 23, no. 10, pp. 3175-3181, 2009.

[8] S. Xu, X. Liu, A. Tabaković, and E. Schlangen, "A novel selfhealing system: towards a sustainable porous asphalt," Journal of Cleaner Production, vol. 259, Article ID 120815, 2020.

[9] J. Li, S. Yang, Y. Muhammad et al., "Fabrication and application of polyurea formaldehyde-bioasphalt microcapsules as a secondary modifier for the preparation of high self-healing rate SBS modified asphalt," Construction and Building Materials, vol. 246, Article ID 118452, 2020.

[10] Q. Liu, S. Wu, and E. Schlangen, "Induction heating of asphalt mastic for crack control," Construction and Building Materials, vol. 41, pp. 345-351, 2013.

[11] Q. Liu, W. Yu, S. Wu, E. Schlangen, and P. Pan, "A comparative study of the induction healing behaviors of hot and warm mix asphalt," Construction and Building Materials, vol. 144, pp. 663-670, 2017.

[12] S. I. Sarsam and H. K. Husain, "Monitoring the impact of micro cracks healing cycles on the deformation of asphalt concrete under repeated loading," in International Congress and Exhibition "Sustainable Civil Infrastructures: Innovative Infrastructure Geotechnology," Springer, Cham, Switzerland, 2017.

[13] Q. Liu, C. Chen, B. Li, Y. Sun, and H. Li, "Heating characteristics and induced healing efficiencies of asphalt mixture via induction and microwave heating," Materials, vol. 11, no. 6, p. 913, 2018.

[14] H. Li, J. Yu, S. Wu et al., "Study on the gradient heating and healing behaviors of asphalt concrete induced by induction heating," Construction and Building Materials, vol. 208, pp. 638-645, 2019.

[15] Q. Liu, E. Schlangen, M. van de Ven, G. van Bochove, and J. van Montfort, "Evaluation of the induction healing effect of porous asphalt concrete through four point bending fatigue test," Construction and Building Materials, vol. 29, pp. 403409, 2012.

[16] Y. Sun, S. Wu, Q. Liu, B. Li, H. Fang, and Q. Ye, "The healing properties of asphalt mixtures suffered moisture damage," Construction and Building Materials, vol. 127, pp. 418-424, 2016.

[17] J. Lin, J. Hong, C. Huang, J. Liu, and S. Wu, "Effectiveness of rejuvenator seal materials on performance of asphalt pavement," Construction and Building Materials, vol. 55, pp. 6368, 2014.

[18] M. Riara, P. Tang, L. Mo, B. Javilla, and S. Wu, "Investigation into crack healing of asphalt mixtures using healing agents," Construction and Building Materials, vol. 161, pp. 45-52, 2018.

[19] U. A. Mannan, M. Ahmad, and R. A. Tarefder, "Influence of moisture conditioning on healing of asphalt binders," Construction and Building Materials, vol. 146, pp. 360-369, 2017.

[20] S.-P. Wu, X.-M. Liu, Q.-S. Ye, and N. Li, "Self-monitoring electrically conductive asphalt-based composite containing carbon fillers," Transactions of Nonferrous Metals Society of China, vol. 16, pp. 512-516, 2006.

[21] G. Leegwater, A. Scarpas, and S. Erkens, "Mechanisms in healing of bitumen and the impact of normal force," in Proceedings of the 8th RILEM International Conference on Mechanisms of Cracking and Debonding in Pavements, Springer, Cham, Switzerland, 2016.

[22] T. Nguyen, E. W. Byrd, D. Bentz, and J. Martin, "In situ spectroscopic study of water at the asphalt/siliceous substrate interface and its implication in stripping," The Journal of Adhesion, vol. 81, no. 1, pp. 1-28, 2005.

[23] M. H. Dehnad, A. Khodaii, and F. Moghadas Nejad, "Moisture sensitivity of asphalt mixtures under different load frequencies and temperatures," Construction and Building Materials, vol. 48, pp. 700-707, 2013.

[24] S. dos Santos, M. N. Partl, and L. D. Poulikakos, "Newly observed effects of water on the microstructures of bitumen surface," Construction and Building Materials, vol. 71, pp. 618-627, 2014.

[25] M. R. Islam and R. A. Tarefder, "Effects of large freeze-thaw cycles on stiffness and tensile strength of asphalt concrete," Journal of Cold Regions Engineering, vol. 30, no. 1, Article ID 06014006, 2016.

[26] H. Behbahani, H. Hamedi, V. N. M. Gilani, and M. Nikookar, "Improving the moisture performance of hot mix glass asphalt by high-density polyethylene as an asphalt binder modifier," International Journal of Sustainable Building Technology and Urban Development, vol. 10, no. 4, pp. 184-193, 2019.

[27] H. Behbahani, G. H. Hamedi, and V. N. Moghaddam Gilani, "Effects of asphalt binder modifying with nano hydrated lime on moisture susceptibility of asphalt mixtures with thermodynamically concepts," Petroleum Science and Technology, vol. 38, no. 4, pp. 297-302, 2020.

[28] M. O. Hamzah, M. R. Kakar, S. A. Quadri, and J. Valentin, "Quantification of moisture sensitivity of warm mix asphalt using image analysis technique," Journal of Cleaner Production, vol. 68, pp. 200-208, 2014.

[29] A. Mehrara and A. Khodaii, "Evaluation of moisture conditioning effect on damage recovery of asphalt mixtures during rest time application," Construction and Building Materials, vol. 98, pp. 294-304, 2015.

[30] Q. Liu, Á. García, E. Schlangen, and M. V. D. Ven, "Induction healing of asphalt mastic and porous asphalt concrete," Construction and Building Materials, vol. 25, no. 9, pp. 3746-3752, 2011. 
[31] B. Gómez-Meijide, H. Ajam, P. Lastra-González, and A. Garcia, "Effect of air voids content on asphalt self-healing via induction and infrared heating," Construction and Building Materials, vol. 126, pp. 957-966, 2016.

[32] J. Norambuena-Contreras and A. Garcia, "Self-healing of asphalt mixture by microwave and induction heating," $M a-$ terials \& Design, vol. 106, pp. 404-414, 2016.

[33] Z. Wang, Q. Dai, and X. Yang, "Integrated computationalexperimental approach for evaluating recovered fracture strength after induction healing of asphalt concrete beam samples," Construction and Building Materials, vol. 106, pp. 700-710, 2016.

[34] Áa García, "Self-healing of open cracks in asphalt mastic," Fuel, vol. 93, pp. 264-272, 2012.

[35] A. Menozzi, A. Garcia, M. N. Partl, G. Tebaldi, and P. Schuetz, "Induction healing of fatigue damage in asphalt test samples," Construction and Building Materials, vol. 74, pp. 162-168, 2015.

[36] H. Li, J. Yu, S. Wu et al., "Effect of moisture conditioning on mechanical and healing properties of inductive asphalt concrete," Construction and Building Materials, vol. 241, Article ID 118139, 2020.

[37] Q. Liu, E. Schlangen, Á. García, and M. van de Ven, "Induction heating of electrically conductive porous asphalt concrete," Construction and Building Materials, vol. 24, no. 7, pp. 1207-1213, 2010.

[38] J. L. Concha and J. Norambuena-Contreras, "Thermophysical properties and heating performance of self-healing asphalt mixture with fibres and its application as a solar collector," Applied Thermal Engineering, vol. 178, p. 115632, 2020.

[39] ASTM D5581-07a(2013), Standard Test Method for Resistance to Plastic Flow of Bituminous Mixtures Using Marshall Apparatus (6 Inch-Diameter Specimen), ASTM International, West Conshohocken, PA, USA, 2013.

[40] ASTM D6927-15, Standard Test Method for Marshall Stability and Flow of Asphalt Mixtures, ASTM International, West Conshohocken, PA, USA, 2015.

[41] V. Najafi Moghaddam Gilani, S. M. Hosseinian, H. Behbahani, and G. H. Hamedi, "Prediction and Paretobased multi-objective optimization of moisture and fatigue damages of asphalt mixtures modified with nano hydrated lime," Construction and Building Materials, vol. 261, Article ID 120509, 2020.

[42] Q. Liu, E. Schlangen, M. van de Ven, and Á. García, "Healing of porous asphalt concrete via induction heating," Road Materials and Pavement Design, vol. 11, no. 1, pp. 527-542, 2010. 